\title{
Evaluation of the Stress Concentration Factor in Butt Welded Joints: A Comparative Study
}

\author{
Miroslav Randić ${ }^{1, * \mathbb{C}}$, Duško Pavletić $^{2}$ and Marko Fabić ${ }^{3}$ \\ 1 Croatian Register of Shipping, 21000 Split, Croatia \\ 2 Faculty of Engineering, University of Rijeka, 51000 Rijeka, Croatia; duskop@riteh.hr \\ 3 Clinical Hospital Center of Rijeka, 51000 Rijeka, Croatia; marko.fabic@gmail.com \\ * Correspondence: miroslav.randic@crs.hr; Tel.: +385-98-328-603
}

check for updates

Citation: Randić, M.; Pavletić, D.; Fabić, M. Evaluation of the Stress Concentration Factor in Butt Welded Joints: A Comparative Study. Metals 2021, 11, 411. https://doi.org/ $10.3390 /$ met11030411

Academic Editor:

Kazuyuki Hokamoto

Received: 9 February 2021

Accepted: 28 February 2021

Published: 3 March 2021

Publisher's Note: MDPI stays neutral with regard to jurisdictional claims in published maps and institutional affiliations.

Copyright: (c) 2021 by the authors. Licensee MDPI, Basel, Switzerland. This article is an open access article distributed under the terms and conditions of the Creative Commons Attribution (CC BY) license (https:// creativecommons.org/licenses/by/ $4.0 /)$.

\begin{abstract}
Surface cracks in butt-welded joints usually occur in places with increased stress concentrations. The stress concentration factor (SCF) can be calculated using an empirical equation, with five geometric parameters of a butt-welded joint (thickness of the base material, toe radius, weld toe angle, weld width, and reinforcement height). However, in an industrial environment, it is impractical and sometimes even impossible to measure all five geometric parameters with sufficient accuracy. In this study, eight experiments on butt-welded joints were performed. All samples were scanned with a 3D scanner, and the geometric sizes of the welded joints were measured using computer software. A modified empirical expression proposed by Ushirokawa and Nakayama was used to calculate the SCF; the expression was adjusted in such a way that the SCF was calculated by knowing only the toe radius. In addition, four new expressions were proposed for the calculation of the SCF by knowing the toe radius in relation to the weld toe angle; the expressions were then compared and analyzed. Additionally, the values of the stress concentrations in the butt-welded joints were obtained using a finite element method (FEM). The SCFs calculated using the four methods were compared and further discussed. Our data suggested a new accurate and straightforward approach for calculating the SCF by knowing only the weld toe radius.
\end{abstract}

Keywords: welded joint; stress concentration factor; toe radius; finite element method

\section{Introduction}

Welding is the most commonly used method for joining metals and is applied in all types of industries, including bridge construction, shipbuilding, house building, the offshore industry, and the car industry. Welding is a relatively fast and inexpensive process in which the weld joint has the same properties as the base material. There are two main types of welding: manual welding and automated welding. A manually welded joint has an irregular shape. Due to sudden changes in geometry and an increase in stress concentrations, this method can lead to surface cracks and, in turn, cracking of the whole welded joint, after which the whole structure around that welded joint may collapse. Surface cracks often occur when the SCF is high [1]. With an increase in the SCF, the risk of creating surface cracks also increases.

Five geometric parameters affect the SCF, including the thickness of the base material, toe radius, weld toe angle, weld width, and reinforcement height [2]. SCFs can be calculated through empirical expressions [3,4]. However, for this method, it is necessary to measure all five geometric parameters; this process can be slow and sometimes barely even feasible, depending on the weld location. There are several ways to measure the geometric dimensions of a welded joint, ranging from conventional methods of measurement (by using simple measuring instruments) to modern 3D scanning approaches to determine geometric properties using computer software. Since the weld toe radius is the most influential geometric variable for the SCF, particular attention is given to its accurate measurement $[5,6]$. Measuring the toe radius with simple measuring devices is the fastest and 
simplest method; however, its accuracy may be questionable [7]. Measuring the geometric dimensions of welded joints with computer software can give the most accurate results; however, this method is complicated and costly and cannot be used to assess welded joints in all locations [8].

After the geometric dimensions of a welded joint have been measured, it is possible to use empirical equations to calculate the SCF in its cross-section. The finite element method (FEM) is used in the modeling of welded joints to analyze the mechanical and geometric characteristics [9]. This is a useful technique for stress analysis in welded joints [10]. Previously, Kiyak et al. [11] calculated SCFs using 2D finite elements, after which they compared those results with the results of empirical equations. Moreover, Ninh Nguyen and Wahab [12] discovered that the toe radius has a significant effect on the SCF, which was confirmed using a FEM. Additionally, Pang obtained similar conclusions, with one addition, i.e., that the weld toe angle has a slightly smaller effect on the SCF [13-15]. The influence of the welding process, parameters, constraints, solid-phase transformation, and multi-pass welding for the thick plate on the distribution of welding deformation and residual stress was analyzed by Rong et al. [16].

In this paper, we propose new expressions for calculating the SCF, taking into account only the toe radius, which is the most influential parameter for the SCF. The SCF can be calculated by knowing only the toe radius, which is essential for practical work, where it is often necessary to determine the SCF quickly to avoid possible initiation of surface cracks. The expressions for calculating the SCF become more accurate if the weld toe angle is known.

\section{Materials and Methods}

A total of eight welding experiments were performed, after which three different welding methods were changed. The following welding methods were changed: the number of cover passes was analyzed in two levels (one pass and three passes); the electrode stick-out length was also analyzed in two levels (5 $\mathrm{mm}$ and $15 \mathrm{~mm}$ ); and experiments were performed with two types of shielding gas (-) mixture of $\left(82 \% \mathrm{Ar}+18 \% \mathrm{CO}_{2}\right)$ and (+) $100 \% \mathrm{CO}_{2}$. The welding methods were modified to obtain different surface shapes of welded joints with different values of the SCF and with different weld toe radii of the welded joints. These welding methods have a significant effect on the surface of a welded joint [17]. Consequently, various forms of welded joints were obtained. Table 1 shows the welding methods that were changed during the experiments, and Table 2 shows the complete test plan.

Table 1. Welding methods that were changed during the experiments.

\begin{tabular}{ccc}
\hline \multirow{2}{*}{ Welding Method } & \multicolumn{2}{c}{ Level } \\
\cline { 2 - 3 } & Lower (-) & Higher (+) \\
\hline Number of cover passes & 1 pass & 3 passes \\
Electrode stick-out length & $5 \mathrm{~mm}$ & $15 \mathrm{~mm}$ \\
Shielding gas & $82 \% \mathrm{Ar}+18 \% \mathrm{CO}_{2}$ & $100 \% \mathrm{CO}_{2}$ \\
\hline
\end{tabular}

Table 2. Experimental plan.

\begin{tabular}{ccccccccc}
\hline Input Factor & \multicolumn{7}{c}{ Sample Label/Input Factor Level } \\
\cline { 2 - 8 } & $\mathbf{1}$ & 2 & 3 & 4 & 5 & 6 & 7 & $\mathbf{8}$ \\
\hline $\begin{array}{c}\text { Number of cover } \\
\text { passes }\end{array}$ & - & - & - & - & + & + & + & + \\
\hline $\begin{array}{c}\text { Electrode stick-out } \\
\text { length }\end{array}$ & - & - & + & + & - & - & + & + \\
\hline Shielding gas & - & + & - & + & - & + & - & + \\
\hline
\end{tabular}




\subsection{Measurement of Geometrical Parameters of Welded Joints}

Welding experiments were performed on samples that were $150 \mathrm{~mm}$ long. For each sample, the geometric parameters of the welded joint were measured using three different bands. Each measured band was $10 \mathrm{~mm}$ wide. The welding parameters were automatically measured and stored during welding. It was found that the welding parameters stabilized a few millimeters after the start of welding. Based on this result, the first band was measured $20 \mathrm{~mm}$ to $30 \mathrm{~mm}$ from the beginning of welding; the second band was measured at the middle of the sample, $70 \mathrm{~mm}$ to $80 \mathrm{~mm}$ from the beginning of welding; and the last band was measured at the end of the sample, $120 \mathrm{~mm}$ to $130 \mathrm{~mm}$ from the beginning of welding.

In each specified band, the geometric dimensions were measured every $1 \mathrm{~mm}$; measurements were taken in 11 cross-sections and in two places (right and left). For each sample, the geometric properties were measured at 66 precisely defined positions. The positions of the bands in which the geometric properties were measured are shown in Figure 1.

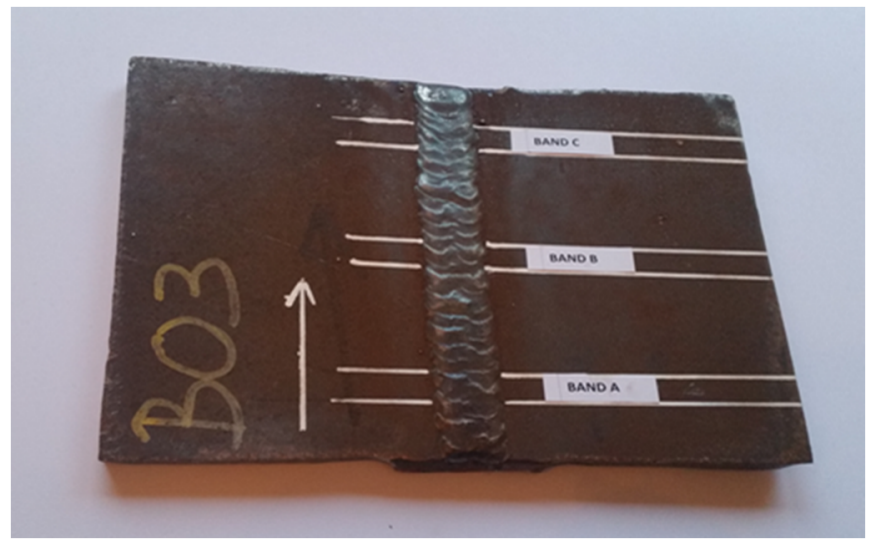

Figure 1. Welding sample with marked measurement areas.

The measurements of the geometric parameters of a welded joint by the computer method were divided into two parts: (1) sample scanning and (2) cross-section analysis of the welded joint using computer software. The surface of each sample was scanned by the "ATOS II Triple Scan" (Advanced Topometric Sensor, Braunschweig, Germany) at the Center for Advanced Computing and Modeling at the University of Rijeka. The computer program "GOM inspect" (GOM GmbH, Braunschweig, Germany), v.2.0.1, was used to measure the geometric dimensions of the welded joint. Briefly, the data obtained by 3D scanning were loaded into a computer, after which the surface of the welded joint was generated [8]. The measured geometric properties of sample A3 in band A are shown in Table 3. 
Table 3. Measured geometric parameters and calculated SCFs for sample A3 in band A.

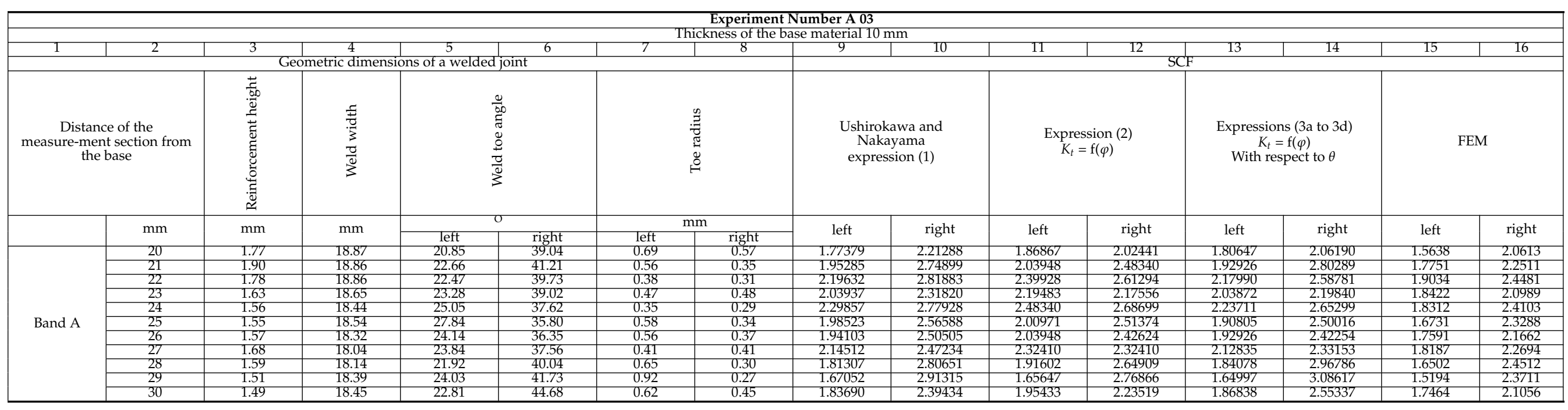




\subsection{Stress Concentration Factor (SCF)}

The SCF is defined by the ratio of the maximum and nominal stress. The surface of a welded joint has an irregular shape with a great number of local shape changes; therefore, it is not easy to calculate the SCF for a welded joint [18]. To date, methods to estimate the SCF in a butt-welded joint have been proposed. The formula proposed by Ushirokawa and Nakayama, which is based on two correction factors (for the weld toe angle and weld toe radius) when calculating the geometric SCF, was used in this paper. Influential geometric quantities of the butt-welded joint was shown in Figure 2. After sorting, the expression for calculating the geometric SCF takes the form (1) $[4,19]$.

$$
\mathrm{SCF}=1+\left(\frac{1-e^{-0.90 \cdot \theta \cdot \sqrt{\frac{t+2 h+0.6 \mathrm{~W}}{2 h}}}}{1-e^{-0.90 \cdot \frac{\pi}{2} \cdot \sqrt{\frac{t+2 h+0.6 \mathrm{~W}}{2 h}}}}\right) \cdot 2 \cdot\left[\left(\frac{h}{\varphi}\right) \cdot \frac{1}{2.8 \cdot \frac{t+2 h+0.6 \mathrm{~W}}{t}-2}\right]^{0.65}
$$

where is: $\mathrm{SCF}$, stress concentration factor; $\varphi$, toe radius; $\theta$, weld toe angle; $W$, weld width; $t$, thickness of the base material, and $h$, reinforcement height.

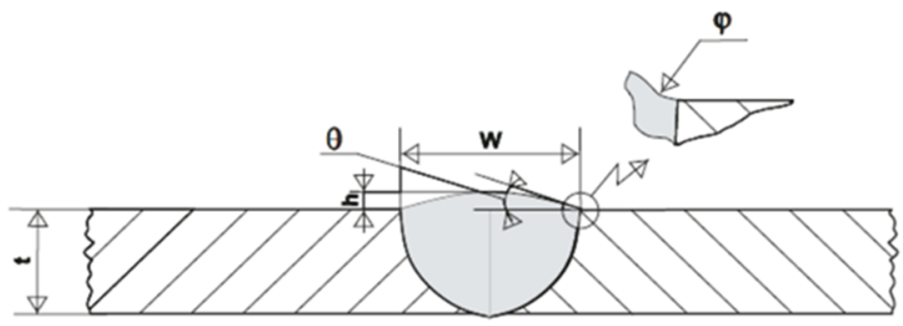

Figure 2. Influential geometric quantities of the butt-welded joint.

In this expression, the SCF is influenced by the toe radius, weld toe angle, weld width, the thickness of the base material, and reinforcement height. These geometric dimensions were obtained by 3D scanning of the welded joint and then measured by "GOM inspect" software. After the geometric properties were assessed, they were included in expression (1), and the concentration factors for the right and left sides of each section in the observed areas on each sample were calculated. Table 3 shows the values of the SCF obtained by expression (1) for sample A3 in band A in columns 9 and 10.

The experiments were performed with eight samples. The SCF was calculated at 66 places on each of the eight samples, and therefore, the SCF was calculated for 528 points. These points are plotted in the diagrams shown in Figure 3a,b. The diagram in Figure 3a shows the trend line, which is a function of the toe radius and SCF. The diagram in Figure $3 \mathrm{~b}$ shows four trend lines that are functions of the toe radius and SCF, which depend on the weld toe angle for values from $0^{\circ}$ to $20^{\circ}$, from $20^{\circ}$ to $30^{\circ}$, from $30^{\circ}$ to $40^{\circ}$, and for the area over $40^{\circ}$. These expressions are shown in Equations (2) and (3a)-(3d), respectively; the values obtained by these expressions are shown in Table 3 for sample A3 in band A in columns 11 to 14 .

$$
\begin{gathered}
K_{t}=1.5996 \cdot \varphi^{-0.419} \\
K_{t}=1.4764 \cdot \varphi^{-0.247} \ldots \text { for angles up to } 20^{\circ} \\
K_{t}=1.6072 \cdot \varphi^{-0.315} \ldots \text { for angles from } 20^{\circ} \text { to } 30^{\circ} \\
K_{t}=1.6719 \cdot \varphi^{-0.373} \ldots \text { for angles from } 30^{\circ} \text { to } 40^{\circ} \\
K_{t}=1.8679 \cdot \varphi^{-0.391} \ldots \text { for angles over } 40^{\circ}
\end{gathered}
$$




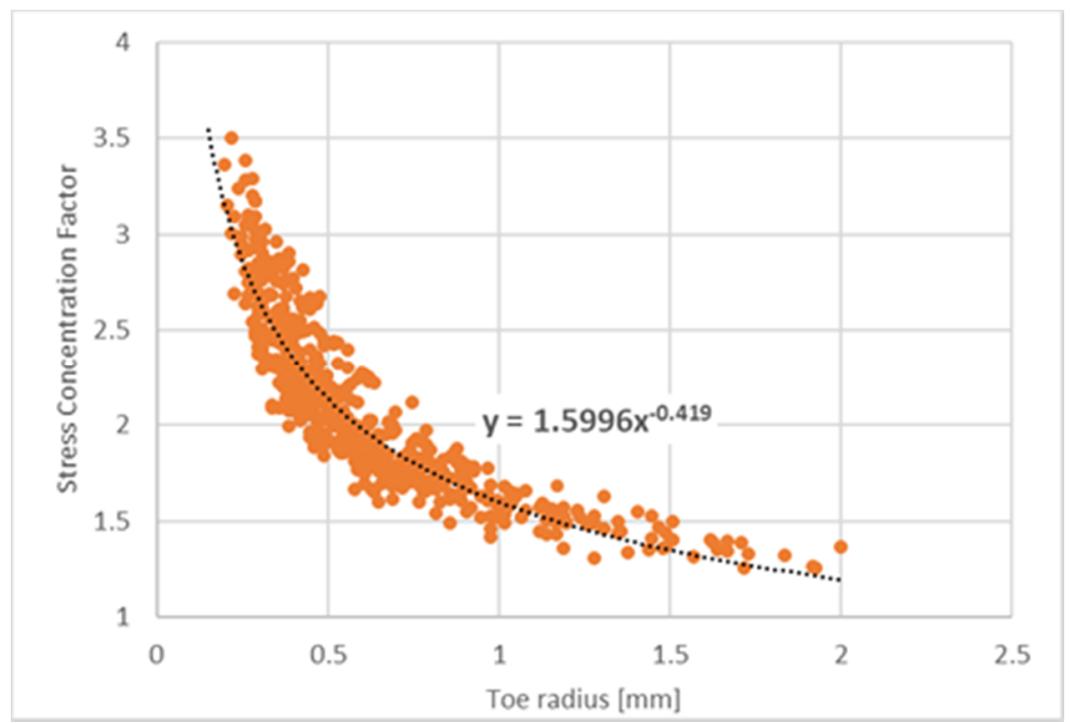

(a)

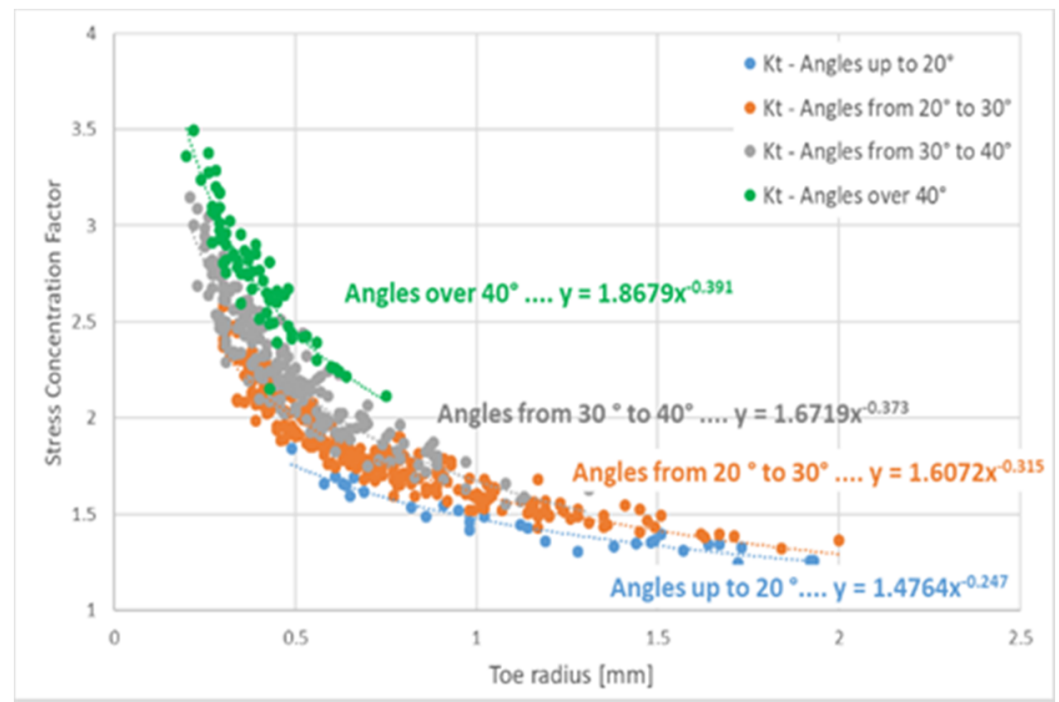

(b)

Figure 3. (a) SCF with respect to toe radius; (b) SCF with respect to the toe radius depend on the weld toe angle for different values.

\subsection{Evaluation of Stress Concentration Using the Finite Element Method (FEM)}

Static structural analyses of a weld seam-stress concentration were performed using FEM. The analyses are performed on the SalomeMeca 2018/CodeAster package (version 14.3.11, "SIXENSE - NECS", Sceaux, France), which allows for a wide variety of simulation scenarios and has a consistent list of verification cases.

The welded joint surface was scanned with a 3D scenario [8], and the obtained geometric model was imported to SalomeMeca 2018/CodeAster [20].

To prepare the surface data for meshing, cleaning of the mesh was required. Surface mesh triangles were adapted in order to obtain good volume mesh quality and surface irregularities, as holes and weld droplets were cleaned, as shown in Figure 4. Since the stress concentration is expected at the weld seam, the mesh is refined. Medium surface mesh has element length scaled-down 2 times, and coarse mesh 4 times. 


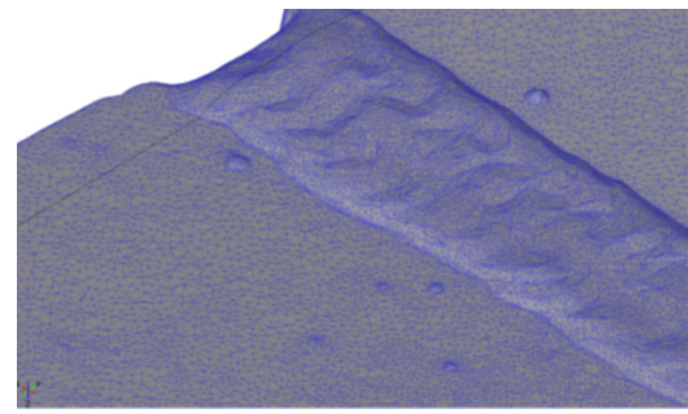

(a)

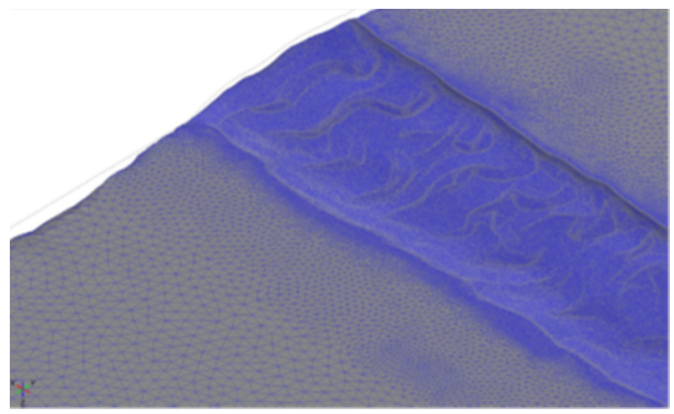

(b)

Figure 4. The appearance of the A3 sample surface shown in Salome software. (a) "uncleaned" surface; (b) surface after holes and weld droplets were cleaned

Mesh convergence was checked in terms of maximum von Mises stress at three different sections (in the middle of each analyzed band, 25, 75, and $125 \mathrm{~mm}$ from the beginning of welding, respectively). The boundary conditions for the model are tensile forces perpendicular to the welded joint.

\section{Results}

Figure 5 shows the A3 sample for which an analysis was conducted using the FEM. The areas before $10 \mathrm{~mm}$ from where welding was initiated and after $140 \mathrm{~mm}$ from the beginning of welding were not analyzed due to uneven ends that could affect the results.

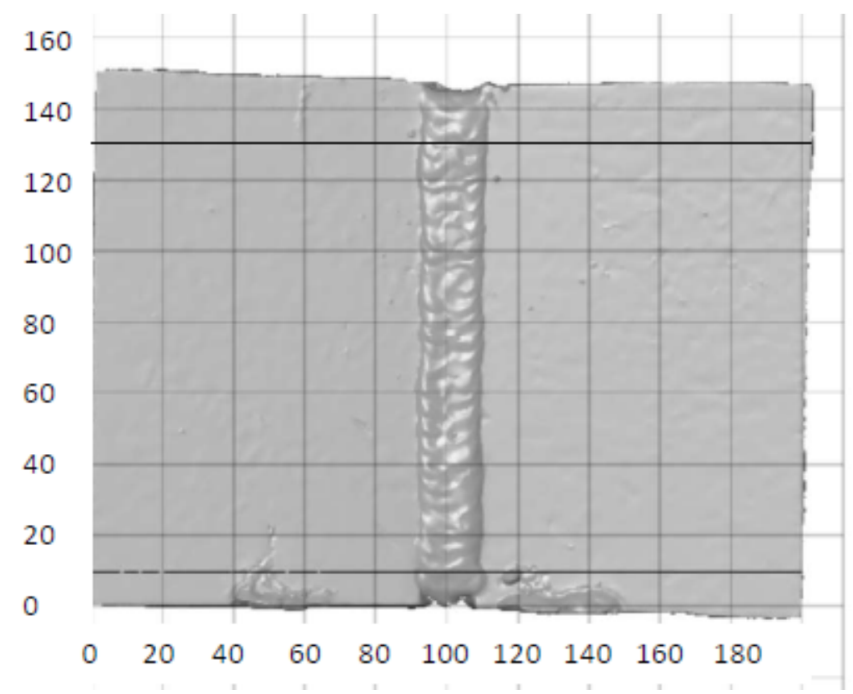

Figure 5. A3 sample shown in GOM inspect.

The mesh obtained by 3D recording (scanning) was loaded into software (Figure 4a). Spry drops were not removed from the surface of the specimen since they did not affect the stress concentration. However, during the finite element method analysis, these spry drops might have an impact in the form of the stress concentration that can form on them; thus, they were cleaned from the finite element model. The cleaned model is shown in Figure $4 \mathrm{~b}$.

The mesh was adapted to the geometry of the welded joints. The mesh was denser in places of sudden changes in geometry. In the area of a welded joint (area with the highest stress concentration), the mesh ranged from 0.01 to $0.03 \mathrm{~mm}$, while in an area of flat sheet metal (area with lower stress concentration), it ranged from 0.03 to $0.09 \mathrm{~mm}$. The values of the SCF obtained by the finite element method are shown for sample A3 in band A in Table 3 in columns 15 and 16. 
Figure 6 shows a comparison of the SCFs obtained using the four different methods. Curve (1) indicates the values of the SCFs obtained using the expressions proposed by Ushirokawa and Nakayama; curve (2) represents the values obtained using expression (2), which takes into consideration only the weld toe radius; curve (3) represents the values obtained by expressions ( 3 a to $\mathrm{d}$ ), which take into account the weld toe radius with respect to the weld toe angle; and curve (4) represents the values obtained using the FEM.

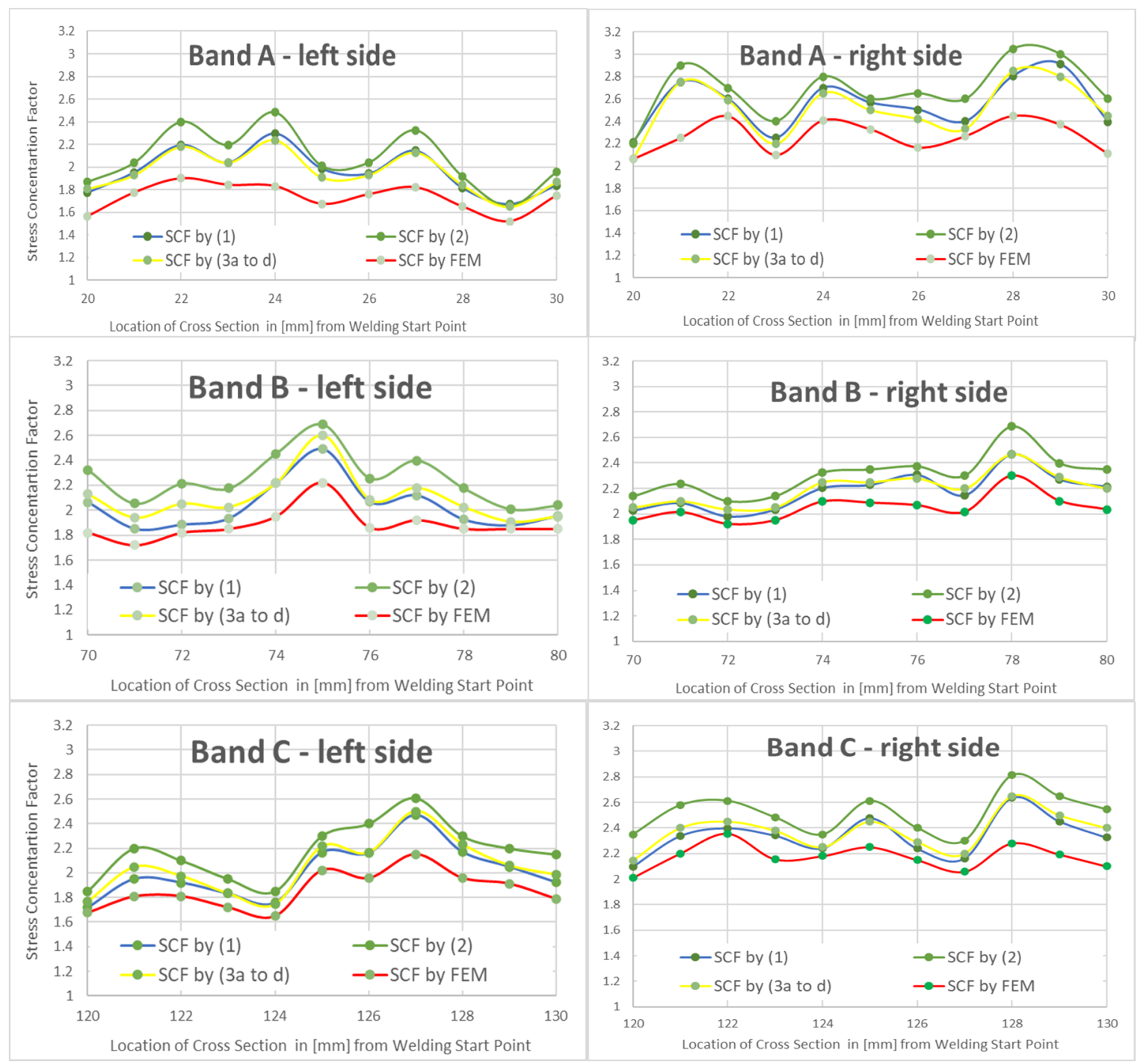

Figure 6. Comparison of SCFs.

\section{Discussion and Conclusions}

In the present study, we proposed and validated new methods for stress concentration factor calculation in butt-weld joints using high-strength steel for operation at low temperatures. However, there is no reason why the methods proposed in the current study could not be used on butt-weld joints of any type of steel. It is not recommended to follow this approach for other materials, such as aluminum and similar materials. These methods can be used for a weld toe radius ranging from $0.20 \mathrm{~mm}$ to $2 \mathrm{~mm}$. Additionally, these methods can be used for a weld toe angle from $10^{\circ}$ to $50^{\circ}$.

In this study, eight samples were welded face to face with various welding techniques, for which the geometric parameters of the welded joints were measured by three different methods. Welding with various welding techniques yielded different forms of welded joints that were used in the analysis. The SCF was obtained in four different ways, and the 
obtained results were compared. The SCF was calculated using an empirical expression by knowing all five geometric properties that have an impact on the SCF. Based on these results, a trend line was obtained as a function of the SCF in relation to the toe radius. Four other trend lines were also obtained as functions of the SCF and the weld toe radius, taking into account the weld toe angle. The fourth way in which the SCF was obtained was by a FEM. The obtained results suggested that the SCF obtained by the FEM was the smallest; nonetheless, all the results were mutually aligned. The results obtained by the expression that considered only the weld toe radius were similar to the results obtained by the expression that considered all five geometric parameters, including the thickness of the base material, toe radius, weld toe angle, weld width, and reinforcement height. Expressions taking into account the weld toe angle gave results that deviated by a maximum of $12 \%$ from the results obtained by the expression for calculating the SCF in which all five geometric parameters were included. The results obtained by the FEM were slightly lower, but these results followed the values of the results obtained by the previous three methods.

This paper suggested a new accurate and straightforward approach for calculating the SCF by knowing only the weld toe radius. Thus, this approach can be appropriate in industrial practice.

Author Contributions: Conceptualization, M.R., D.P., and M.F.; methodology, M.R.; software, M.F.; validation, D.P.; formal analysis, M.R.; investigation, M.R.; resources, M.R.; data curation, M.R.; writing—original draft preparation, M.R.; writing—review and editing, D.P.; visualization, M.R.; supervision, D.P.; project administration, M.F.; funding acquisition, D.P. All authors have read and agreed to the published version of the manuscript.

Funding: This work was supported by the Croatian Science Foundation under project IP-2018-013739 and the University of Rijeka (contract nos. uniri-tehnic-18-33 and uniri-tehnic-18-107).

Institutional Review Board Statement: Not applicable.

Informed Consent Statement: Not applicable.

Data Availability Statement: Data available in a publicly accessible repository.

Conflicts of Interest: The authors declare no conflict of interest.

\section{References}

1. Lawrence, F.V. Estimation of Fatigue-Crack Propagation Life in Butt Welds. Weld. Res. Suppl. 1973, 52, 212-220.

2. Radaj, D.; Sonsino, C.M.; Fricke, W. Fatigue Assessment of Welded Joints by Local Approaches; Woodhead Publishing Ltd.: Cambridge, UK, 2006; p. 183.

3. Fujisaki, W.; Noda, N.; Tanaka, H.; Nisitani, H. Effects of Reinforcement Geometry and Welding Condition on Stress Concentration Factor of Butt Welded Joint. J. Soc. Mater. Sci. Jpn. 1990, 39, 1533-1538. [CrossRef]

4. Ilda, K.; Uemura, T. Stress Concentration Factor Formulae Widely Used in Japan. Fatigue Fract. Eng. Mater. Struct. 1996, 19, 779-786.

5. Harati, E.; Svensson, L.-E.; Karlsson, L. The Measurement of Weld Toe Radius Using Three Non-destructive Techniques. In Proceedings of the 6th International Swedish Production Symposium, Stoskholm, Sweden, 16-18 September 2014.

6. Groš, J.; Medić, S.; Brozović, M. Metode trodimenzionalnog optičkog mjerenja i kontrole geometrije oblika. Zb. Veleučilišta U Karlov. 2012, 1, 43-48. (In Croatian)

7. Randić, M.; Pavletić, D.; Turkalj, G. The Measurement of Weld Surface Geometry. In Proceedings of the XVII simpozij International Maritime Association of the Mediteranean, Lisabon, Portugal, 9-11 October 2017.

8. Randić, M.; Pavletić, D.; Turkalj, G. Multiparametric investigation of welding techniques on toe radius of high strength steel at low-temperature levels using 3D-scanning techniques. Metals 2019, 9, 1355. [CrossRef]

9. Marques, S.V.E.; Silva, J.G.F.; Pereira, A.B. Comparison of Finite Element Methods in Fusion Welding Processes-A Review. Metals 2020, 10, 75. [CrossRef]

10. Pavani, P.; Sivasankar, P.; Lokanadham, P.; Uma Mhahesh, P. Finite Element Analysis of Residual Stress in Butt Welding of Two Similar Plates. Int. Res. J. Eng. Technol. 2015, 2, 57-60.

11. Kiyak, Y.; Madia, M.; Zerbst, U. Extended Parametric Equations for Weld Toe Sress Concentration Factors and Through-thickness Stress Distributions in Butt-welded Plates Subject to Tensile and Bending Loading. Weld World 2016, 16, 1247-1259. [CrossRef]

12. Ninh Nguyen, T.; Wahab, M.A. Theoretical Study of the Effect of Weld Geometry Parameters on Fatigue Crack Propagation Life. Eng. Fract. Mech. 1995, 51, 1-18. [CrossRef] 
13. Pang, H.L.J. Analysis of Weld Toe Radius Effects on Fatigue Weld Toe Cracks. Int. J. Press. Vessel. Pip. 1994, 58, 171-177. [CrossRef]

14. Pang, H.L.J. Analysis of Weld Toe Profiles and Weld Toe Cracks. Int. J. Fatique 1993, 15, 31-36. [CrossRef]

15. Cerit, M.; Kokumer, O.; Genel, K. Stress Concentration Effects of Undercut Defect and Reinforcement Metal in Butt Welded Joint. Eng. Fail. Anal. 2010, 17, 571-578. [CrossRef]

16. Rong, Y.; Xu, J.; Huang, Y.; Zhang, G. Review on finite element analysis of welding deformation and residual stress. Sci. Technol. Weld. Join. 2018, 23, 198-208. [CrossRef]

17. Jeffus, L. Welding Principles and Applications, 7th ed.; Delmar: New York, NY, USA, 2012.

18. Niemi, E.; Fricke, W.; Maddox, S.J. Fatigue Analysis of Welded Components; Woodhead Publishing Ltd.: Cambridge, UK, 2006.

19. Ushirokawa, O.; Nakayama, E. Stress concentration factor at Welded Joints. Ishikawajima-Harima Eng. Rev. 1983, $23,98-103$.

20. Thakore, D. Finite Element Analysis with Open Source Software; Moonish Enterprises Pty Ltd.: Brisbene, Australia, 2014. 